\title{
Optimization of Main Public Transport Paths Based on Accessibility- Case Study: Mashhad, Iran
}

\author{
Houman Shadab Mehr, Mohamad Rahim Rahnama, Mohamad Ajza Shokouhi, \\ and Ezatollah Mafi \\ Ferdowsi University of Mashhad
}

\begin{abstract}
Transport planning is an important aspect of urban planning. In this regard, enhancement of public transport systems and guiding urban travels towards them has found a crucial role in traffic improvement, preventing capital waste, and achieving sustainable cities. Mashhad, Iran, the second largest city in Iran, with a population of three million, has two main systems of public transport, light rail transit (LRT) and bus rapid transit (BRT). In designing these lines, not enough attention was paid to urban sustainability principles and maximizing access. The aim of this study was to redesign the main public transport lines using the approach of accessibility enhancement. The meta-heuristic method of Ant Colony Optimization was applied for this purpose. To compare the redesigned paths with the current paths, access indicators were defined and computed in the case of two alternatives. The results show that the access indicator in the modified alternative is significantly higher than the current one.
\end{abstract}

\section{Introduction}

Traffic density is one of the main problems of big cities in developing countries (Pardo 2010). Regarding the high cost of transport and its profound impact on the economy of a country, this issue is one the most important subjects studied in different societies (Behbahani and Asadikiya 2010). Therefore, transport planning is an important aspect of urban planning. In this regard, enhancement of public transport systems and guiding urban travels towards them has found a crucial role in decreasing traffic problems. In fact, public transport as a basic component of urban transport has played an undeniable role in improving living conditions in cities, such that imagining a medium or large city without it seems impossible. In large cities of the world, public transport constitutes $50 \%$ of urban travel. Nowadays, urban planners, to respond to people displacement requirements, have established urban development patterns on the basis of public transport and its expansion. 


\section{Research Location}

The study took place in Mashad, Iran, the second largest city in Iran, with a resident population of 3 million and more than 20 million pilgrims yearly. The city has a relatively high vehicle density, and traffic has increased rapidly in recent years. Related to transit, the situation of Mashhad is representative of many cities in developing countries. Figure 1 illustrates location of Mashhad.

FIGURE 1.

Location of Mashhad

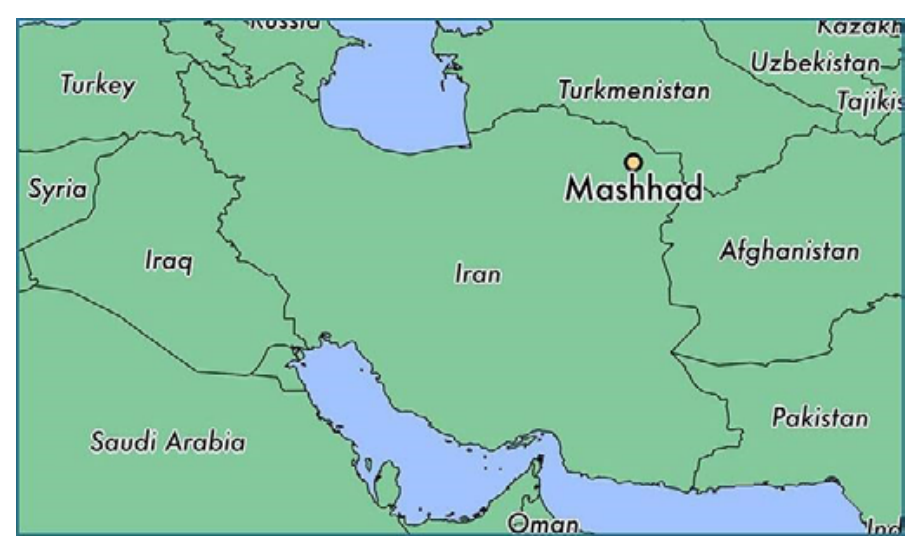

The main public transport systems of Mashhad are bus rapid transit (BRT) and light rail transit (LRT), referred in this paper as the framework of public transport. In the planning for Mashhad, four BRT and four LRT lines were predicted (see Figure 2). To date, lines BRT1 and LRT1 have been constructed and line BRT2 and LRT2 are under construction. According to plans, all lines must be constructed and implemented in the next 10 years.

FIGURE 2.

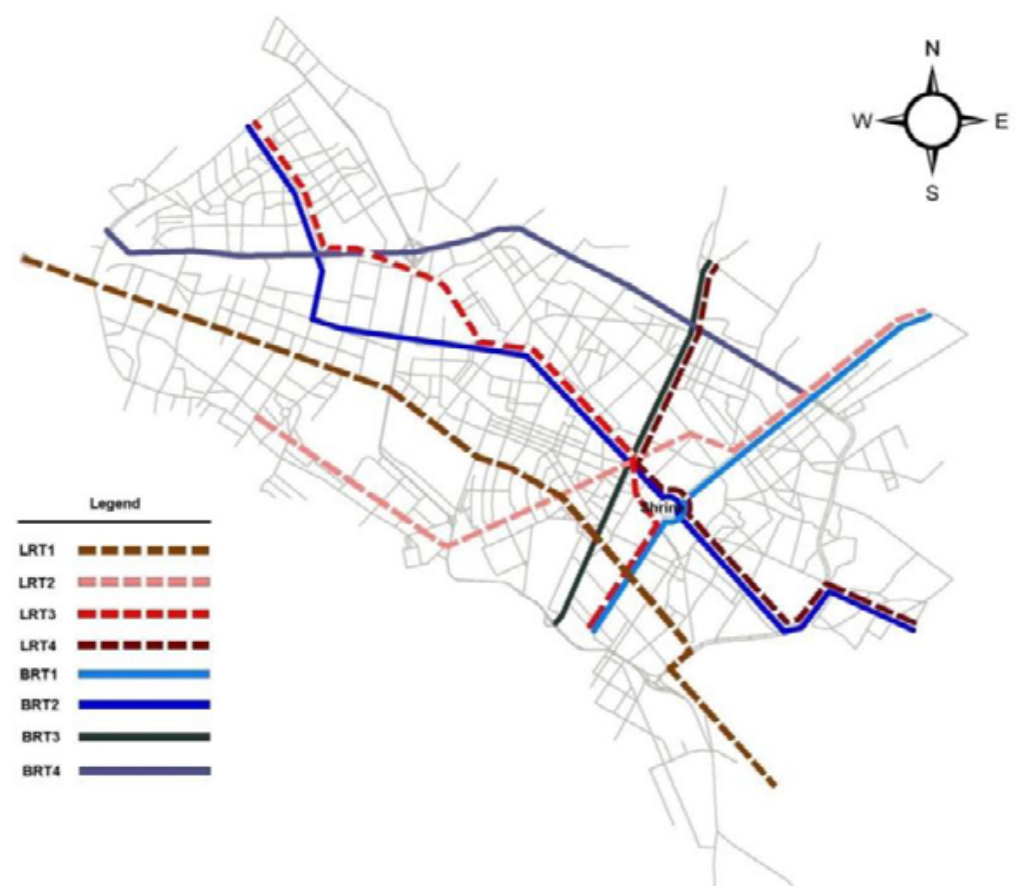

Source: Transport Research Center of Sharif Industrial University 2003, 2008 


\section{Research Problem}

In determining the current lines of the public transport framework of Mashhad, sustainable city principles and geographical properties of the city have not been sufficiently considered. As can be seen in Figure 2, the current paths of the LRT and BRT lines overlap in most places ( $50 \%$ of their length), which results in a reduction in the coverage area of the system. Overlapping of main public transport lines is not a problem by itself, as this condition exists in many large cities, but financing problems and limitations have led to the limitation of public transport in Mashhad. In these circumstances, concentration of public transport facilities into one or several paths will result in the impossibility of their development in the rest of the regions. Also, the objective of the current LRT and BRT lines of Mashhad was based on traffic index improvements, such as an increase in the average speed in the street network. The paths of these lines were determined by optimizing the traffic indices and maximizing the mobility characteristics of the city.

\section{Research Objective}

The aim of this study was to modify the current framework of the Mashhad public transport system and resolve its problems based on sustainable city principles and consideration of accessibility over mobility concepts, with special attention to the geographical characteristics of urban areas such as the settlement and employment centers of city and geometrical properties of the street network.

\section{Research Background}

The problem of optimizing the public transport paths of large networks is a complicated issue that cannot be solved by the ordinary optimization methods in mathematics (Hosapujari and Verma 2013). Various problems in solving public transport optimization include non-linearity, state of being non-convex, multi-target function, and the like (Ayati and Bagheri 2006). One innovative method for solving the optimization problem of public transport paths was presented by Mandl (1979), comprising two steps. In the first step, a primary possible network is created, and in the second step, a target function in the form of the total time of travelers, including on-means time and waiting time, is minimized. This algorithm does not consider the travel demand in the network construction stage. In Mandl's algorithm, the emphasis is on the network's coverage and direct paths (Mandl 1979).

Throughout following years, other methods were proposed for solving these problems, such as localizing a path from the rapid transit system with population coverage insight considering interstation distances and source-destination demand.

For Mashhad, two studies were conducted by the Transport Research Center of Sharif Industrial University. In the first study, to present good rail alternatives for Mashhad, comments from responsible authorities and experts of the Mashhad transport system were collected on the LRT paths with a high probability of construction. Alternatives were presented according to criteria such as movement tendency lines, potential capacity of different paths, authority comments, and expert analysis and the possibility of the development and expansion of the lines. The study resulted in the determination 
of four paths for the LRT system of Mashhad (Transport Research Center of Sharif Industrial University 2003).

The second study focused on the design of BRT lines in Mashhad. The street network of the city was updated and, by estimations of population, car ownership, average number of people on board, and statistics on volume and passenger counting in shear lines, the information on travel demand also was updated. Different choices of bus networks were created, and a multi-target assessment was applied. The final alternative was determined after controlling the results of traffic allocation to the network using EMME/2 software and evaluation of traffic indices (Transport Research Center of Sharif Industrial University 2008).

\section{Theoretical Basis}

The theory behind the present study is for a sustainable city with emphasis on increased accessibility (justified distribution of public transport service). It is worth noting that for development of public transport systems, consideration of the accessibility parameter is crucial.

One of the most important subjects in urban studies is justified access to facilities (Rahnam and Aghajani 2013). The aim of accessibility planning is reaching sustainable development by transitioning from mobility or speed increase to accessibility or reducing the distance between home and office, resulting in decreased fuel consumption and environmental pollution. Therefore, accessibility planning is a tool for achieving sustainable development (Rahnam and Forghani 2008).

The accessibility concept has been considered from different aspects such as physical, mental, economic, and financial, which could be related to the functional nature of the land and transport network (Kaphle 2006). Accessibility has been addressed as one of the functional axes for the spatial shape of cities. Contemporary theorists have noted accessibility as one of the main advantages of urban areas, and most theories on the appearance and function of cities note it as an evident fact. Moreover, development based on transport properties along with rail public transport has been recognized as a method for sustainable development of metropolitan areas. In comparison with cities that are dependent on personal transport, development, along with precise and correct design and implementation of public transport systems, could continuously reduce traffic and prevent urban scattering due to increased population, such that transportbased development is considered a method for sustainable development (Xiaosu and Hong 2013).

\section{Research Methodology}

To redesign the LRT and BRT lines, Ant Colony Optimization (ACO) was applied. The mean distance from the zone center to the nearest LRT or BRT line was measured in case of current and modified alternatives $\left(D_{c}\right.$ and $\left.D_{m}\right)$. To calculate the mentioned distances, GIS software was used, and the Hansen method was applied to compute the access indicator $\left(I_{a}\right)$. Finally, to compare the $I_{a}$ in case of the current and modified alternatives, an independent sample t-test using SPSS software was used. 


\section{Ant Colony Algorithm}

Transit systems sometimes are designed using very detailed cost models (Uchimuri, Takashi, and Saitoh 2002). Designing a public transport network is a sophisticated issue, so, in general, metaheuristic methods are used (Sivakumaran, Cassidy, and Madanat 2014). These methods, including genetic algorithm, ACO, and simulated cooling and warming algorithms, have been used widely for public transport network design and have led to appropriate answers for large-scale problems. In this research, redesign of the LRT and BRT lines of Mashhad was conducted using ACO.

Differentiating this study from those conducted previously is the target function of the algorithm.

Ant colonies or social insect societies have a highly-structured social organization. One of the results of this organization is carrying out complicated tasks and resolving problems of daily life, which are more than the ability of an individual ant (Dorigo, Maniezzo, and Colorni 1996). These types of behaviors observed in specific groups of insects are called "swarm intelligence" (Ghoseiri and Morshedsolouk 2006). ACO was developed by an experiment performed by Goss et al. in 1989, who were inspired by the behavior of ants in optimizing the path from the ant nest to food resources. In moving from the nest to a food resource, the ants release pheromones, which disappear after a while. Therefore, as time passes, the more-used paths will have higher amounts of pheromones and the low traffic paths would be eliminated (Goss et al. 1998). (For further information on ACO, refer to Dorigo and Stutzle 2004). The algorithm of public transport path determination includes a desirable function and several limitations. Path lines are defined on the street network, which includes a series of nodes (junctions) and arcs (streets). The algorithm is written in a way such that each path line is determined in a node-to-node format according to the desired function that would satisfy the defined limitations.

\section{Research Variables}

The research variables were selected to make it possible to modify the LRT and BRT paths based on enhancing the relationship of settlement centers with travel centers. To determine the research variables, Mashhad was divided into 253 zones, as shown in Figure 3. 
FIGURE 3.

Mashhad city zoning in

GIS environment

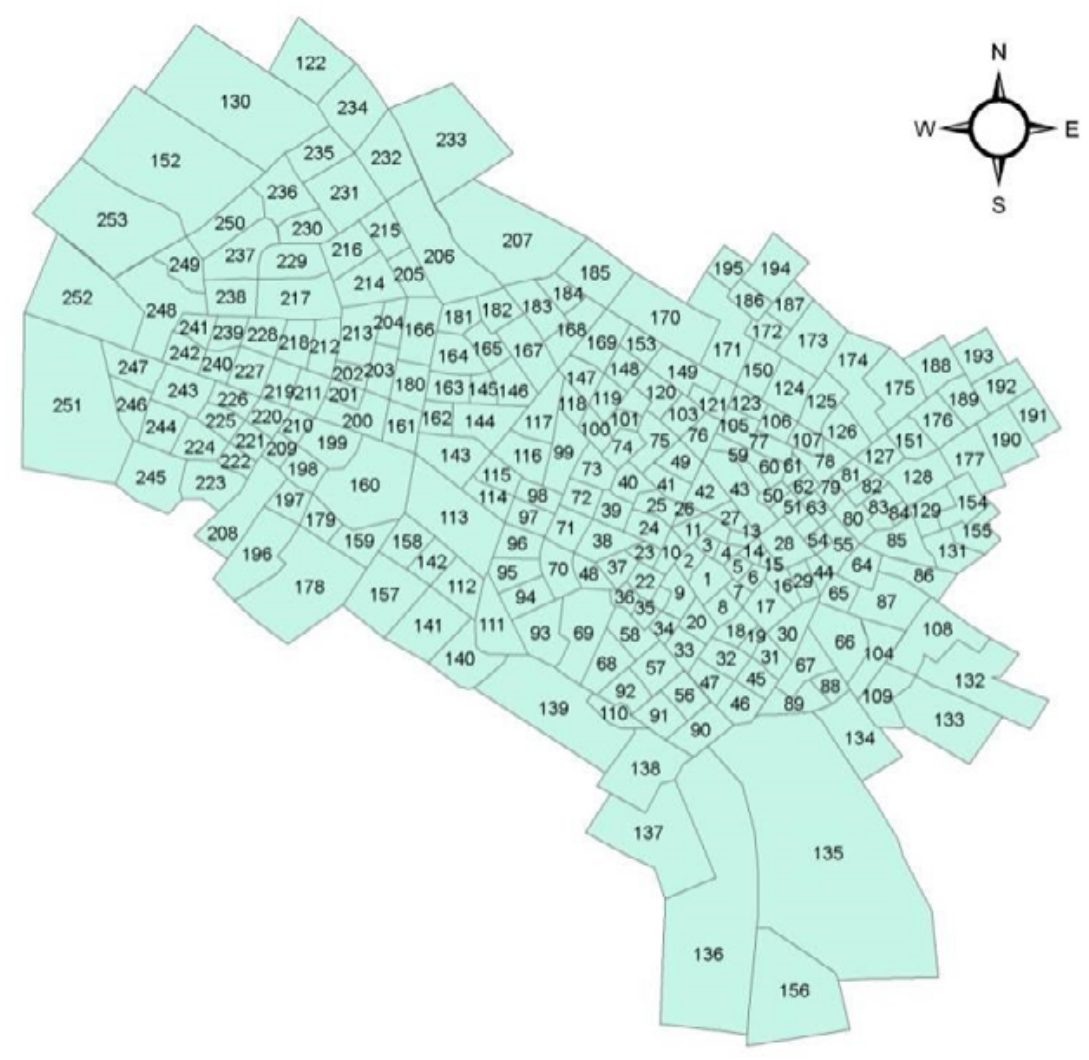

Research variables were defined as follows:

- $\quad P_{\mathrm{i}}$ : population of zones

- $\mathrm{W}_{\mathrm{j}}$ : number of employed people in job location

- $\mathrm{VK}_{\mathrm{j}}$ : number of business units in zones (representing commercial application)

- $\mathrm{K}_{\mathrm{j}}$ : number of the clerks in the job location (representing of administrative application)

- $A P A R K_{j}$ : park areas in zones (representing recreational application)

It must be noted that education is an important travel-absorbing application, but due to attempts of urban planners to guide these travels towards walking or cycling travels (via closing up the distances between homes and schools), it has not been regarded as a determining factor in defining the public transport line framework.

All variables were estimated for each of the 253 zones in timetable of the project (2026).

\section{Values of Variables}

The values of the variables are presented graphically for the 253 zones in Figures 4 through 8 , which show the variable value range of $\mathrm{P}_{\mathrm{i}}, \mathrm{W}_{\mathrm{j}}, \mathrm{VK}_{\mathrm{j}}, \mathrm{K}_{\mathrm{j}}$, and $A P A R K_{j}$ in the zones consecutively. The variables of the research were derived from the Mashhad transport comprehensive studies database and entered into GIS software. 
FIGURE 4.

Variable value ranges of population $\left(\mathrm{P}_{\mathrm{i}}\right)$

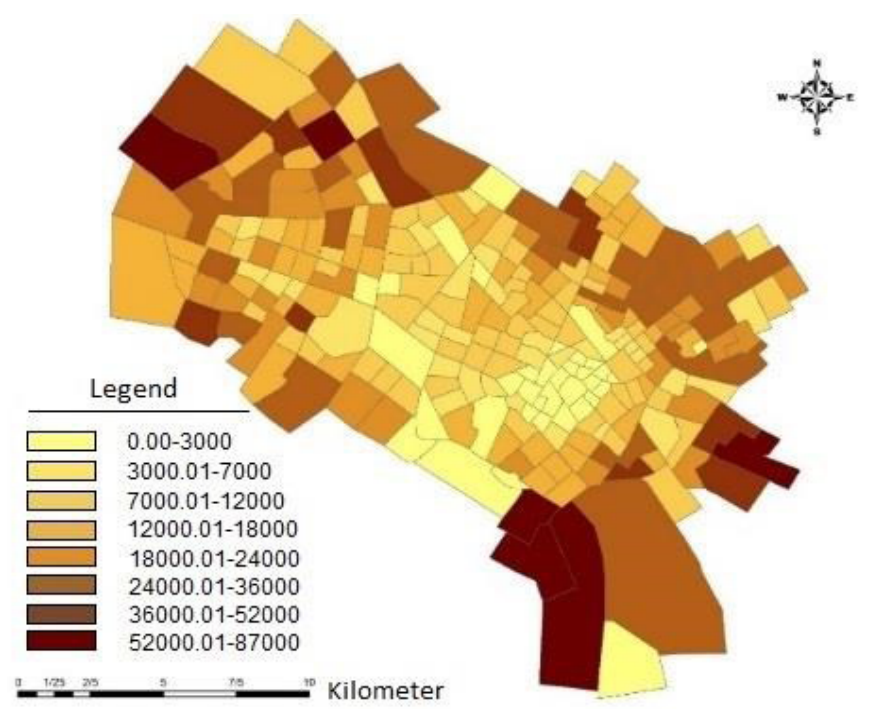

FIGURE 5.

Variable value ranges of employed people in job locations $\left(\mathrm{W}_{\mathrm{j}}\right)$

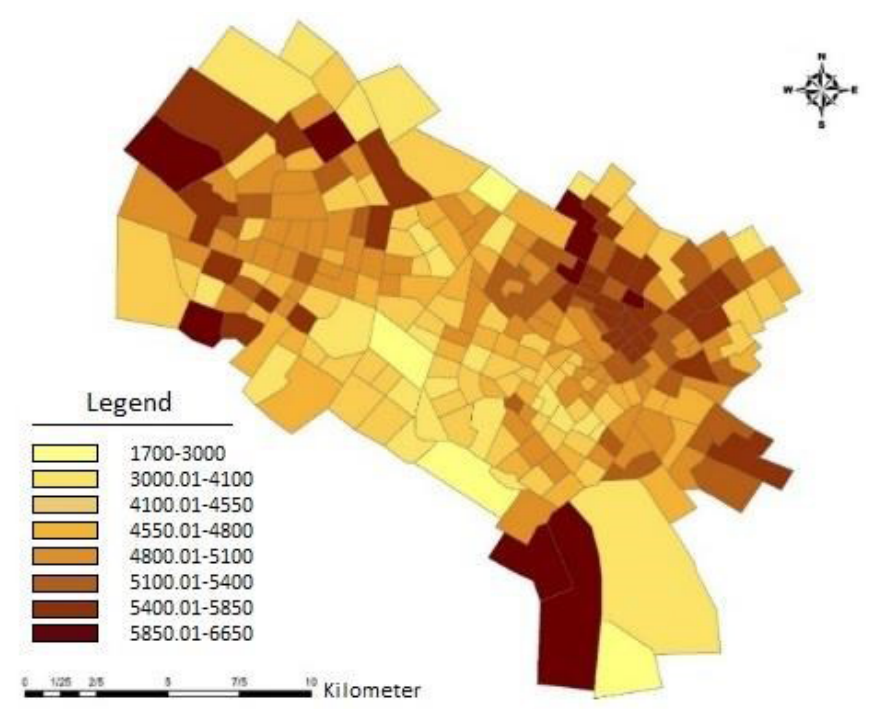

FIGURE 6.

Variable value ranges of business units $\left(\mathrm{VK}_{\mathrm{j}}\right)$

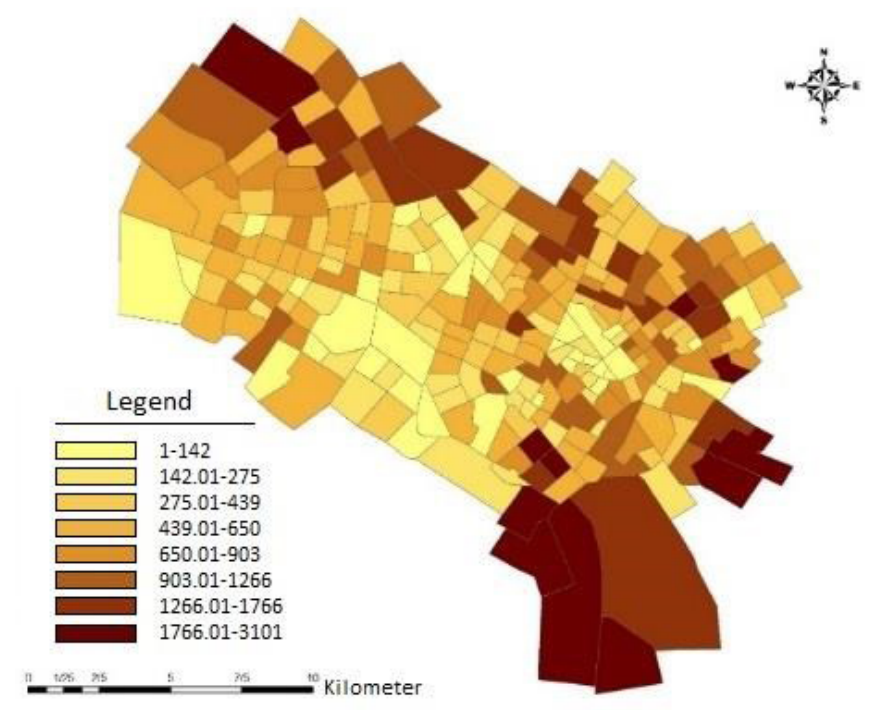


FIGURE 7.

Variable value ranges of clerks in job location $\left(\mathrm{K}_{\mathrm{j}}\right)$

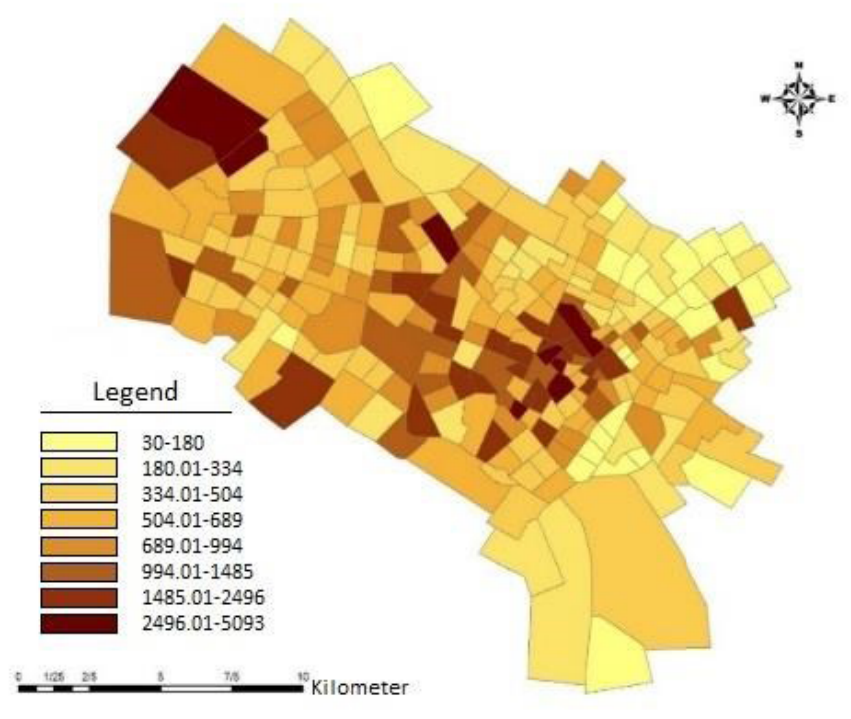

FIGURE 8.

Variable value ranges of park areas $\left(A P A R K_{j}\right)$

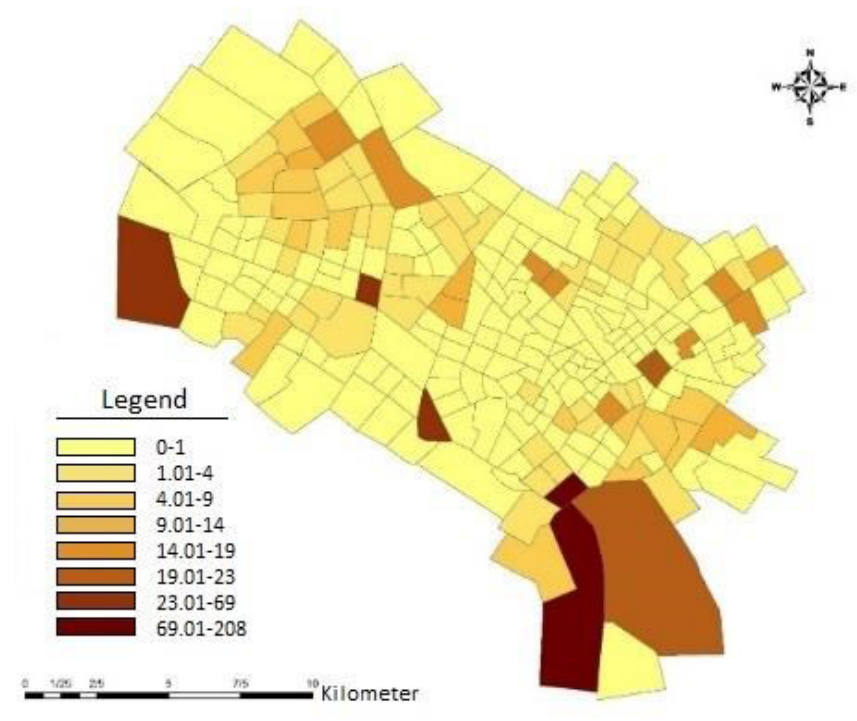

\section{Redesign of LRT and BRT Lines Using ACO}

\section{Desirability Function}

Choosing an arc by an ant depends on the desirability of that arc (its advantages). The desirability function of every arc of the network includes two parts: the amount of pheromones on the arc and the advantages of the end node of the arc, which includes population and the level of travel absorbing applications in the vicinity of that node. Equation 1 shows the desirability function:

$$
U_{i j}=\tau_{i j}+p_{j}+k_{j}
$$


where $U_{i j}$ is the desirability related to selection of $j$ node from select node of $i$ (or [i,j] $\operatorname{arc}), \tau_{i j}$ is the amount of pheromone on the $(i, j)$ arc, $P_{j}$ is the population in the vicinity of the $j^{\text {th }}$ node, and $\mathrm{k}_{\mathrm{j}}$ is the level of travel-absorbing application in the vicinity of the $j^{\text {th }}$ node.

The probability equation of choosing an arc by an ant via a logit model is defined as follows:

$$
p_{i j}=\frac{e^{U i j}}{\sum_{(i, j) \in(\text { feasible })_{i}} e^{U i j}}
$$

where $P_{i j}$ is the probability of choosing $j^{\text {th }}$ node from $\mathrm{i}^{\text {th }}$ node $((\mathrm{i}, \mathrm{j}) \text { arc) and (feasible })_{\mathrm{i}}$ indicates the series of arcs for the $\mathrm{i}^{\text {th }}$ node that satisfy the condition, and $\mathrm{U}_{\mathrm{i}, \mathrm{j}}$ is calculated from Equation (1).

Pheromonization is done by means of the paths in the previous iterations. For selecting each arc, 100 iterations were done.

\section{Limitations}

In addition to the limitations related to the physical properties of the passages that must have the capability for LRT and BRT traffic, the other important limitation is associated with budget. Normally, a budget limitation is applied via limiting the line length. In this study, as the objective was to compare the proposed line paths with the current ones, it was assumed that the length of the proposed lines differ with the current lines by only $5 \%$. Also, as the paths of LRT lines 1 and 2 were implemented in the earth, they are assumed to be fixed and unchangeable.

\section{Algorithm Implementation}

The algorithm was run in the environment using MATLAB software to determine the path in a node-to-node (junction-to-junction) format. Thus, the possibility of manual modification of the path in any network node (due to specific conditions undefined in the algorithm) was predicted, i.e., if in the process of path provision, modification of a specific node is required, the modifications will be applied in the system and the next node will be determined by the software. This process is repeated throughout the path. Figure 9 shows the LRT and BRT paths that resulted from the research algorithm. The characteristics (length and level of overlap) of the BRT and LRT paths of Mashhad in the current condition and the modified levels are presented in Table 1. 
FIGURE 9.

Modified paths of public transport framework on Mashad street network

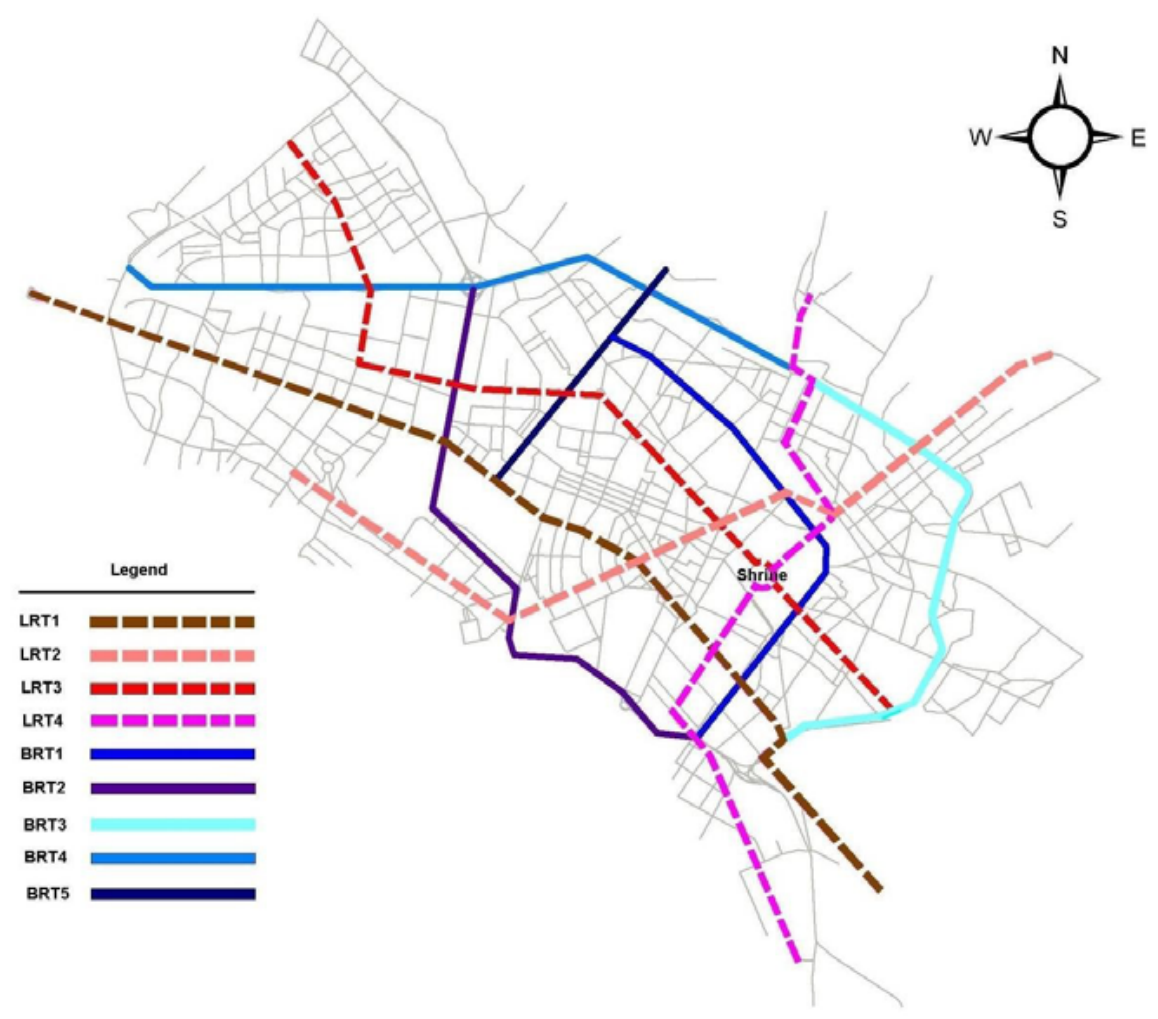

TABLE 1.

Comparison of Current LRT and BRT lines with Modified Alternative

\begin{tabular}{|l|r|r|r|}
\hline \multirow{2}{*}{$\begin{array}{c}\text { Main Public } \\
\text { Transport Lines }\end{array}$} & $\begin{array}{c}\text { Line Length } \\
(\mathrm{m})\end{array}$ & $\begin{array}{c}\text { Cverlap Path Length } \\
(\mathrm{m})\end{array}$ & $\begin{array}{c}\text { Difference of Modified Alternative } \\
\text { Relative to Current Choice (\%) }\end{array}$ \\
\cline { 2 - 4 } Current lines & 75,668 & 32,086 & \\
\hline LRT & 63,162 & 32,086 & - \\
\hline BRT & 138,830 & 64,172 & - \\
\hline BRT and LRT & 79,841 & 0 & +5.51 \\
\hline Modified lines & 57,533 & 0 & -8.91 \\
\hline LRT & 137,374 & 0 & -1.05 \\
\hline BRT & & 0 & \\
\hline LRT and BRT & & 0 & \\
\hline
\end{tabular}

\section{Computation of Access Indicator}

The ultimate goal of most transportation is "access," the ability to reach desired goods, services, and activities. Transportation decisions often involve tradeoffs between different forms of access (Litman 2011). Accessibility expresses the relationship between the land use system and the transportation system serving it (Nuzzolo, Coppola, and Papa 2014).

A review of accessibility measures by Handy and Niemeier (1997) suggests three general categories of measures: gravity-based measures, cumulative opportunity measures, 
and behavioral measures. Gravity-based measures are derived from the gravity model of spatial interaction. In deriving gravity-based measures of accessibility, destination opportunities such as employment are weighted by the cost of their interaction, which usually is specified by the distance decay function component of the gravity model, often taking on the familiar negative exponential form. Thus, a measure of Hansen (1959) accessibility, which is based on the gravity model, could be specified as:

$$
A_{i k}=\sum W_{k j} f_{i j}
$$

where $i$ and $j$ are subareas, $W_{k}$ is a total population of opportunities, and $W_{k j}$ is a subpopulation of opportunities (Harris 2001). The function $\mathrm{f}_{\mathrm{ij}}$ represents the cost of travel as impedance to interaction.

Equation (4) was developed based on the above general equation:

$$
A_{t}=A_{p i}+A_{e j}
$$

where $A_{t}$ is the total access index, $A_{i}$ is the access index related to population on origin $i$ (equation N.5), and $A_{e j}$ is the access index related to employment at destination $j$ (Equation [6]).

$$
A_{p i}=\sum_{i=1}^{n} P_{i} d_{i}^{-2}
$$

where $n$ is number of zones (253), $P_{i}$ is population on origin $\mathrm{i}$, and $d_{i}$ is distance from the center of the zone $i$ to the nearest LRT or BRT line.

$$
A_{e j}=\sum_{j=1}^{n} E_{j} d_{i}^{-2}
$$

where $E_{j}$ is employment at destination (zone $\mathrm{j}$ ).

The mean distance from zone center to the nearest LRT or BRT line were measured, and then the access level to the LRT and BRT network in the cases of the current $\left(A_{c}\right)$ and modified $\left(A_{m}\right)$ alternatives were calculated separately for each zone using equations 4,5 , and 6.

The value ranges of $A_{c}$ and $A_{m}$ are presented graphically for the 253 zones of the city in Figures 10 and 11 , which show the $A_{c}$ and $A_{m}$ ranges in the zones consecutively. 
FIGURE 10.

Value ranges of $A_{C}$ in zones

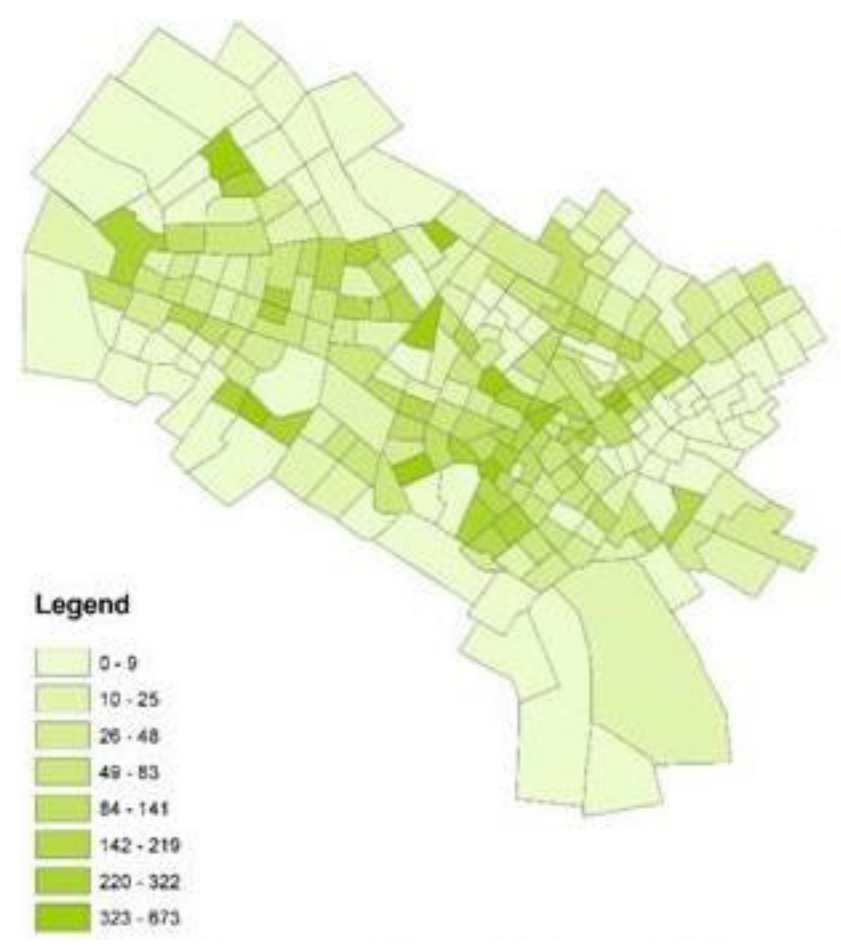

FIGURE 11.

Value ranges of $A_{m}$ in zones

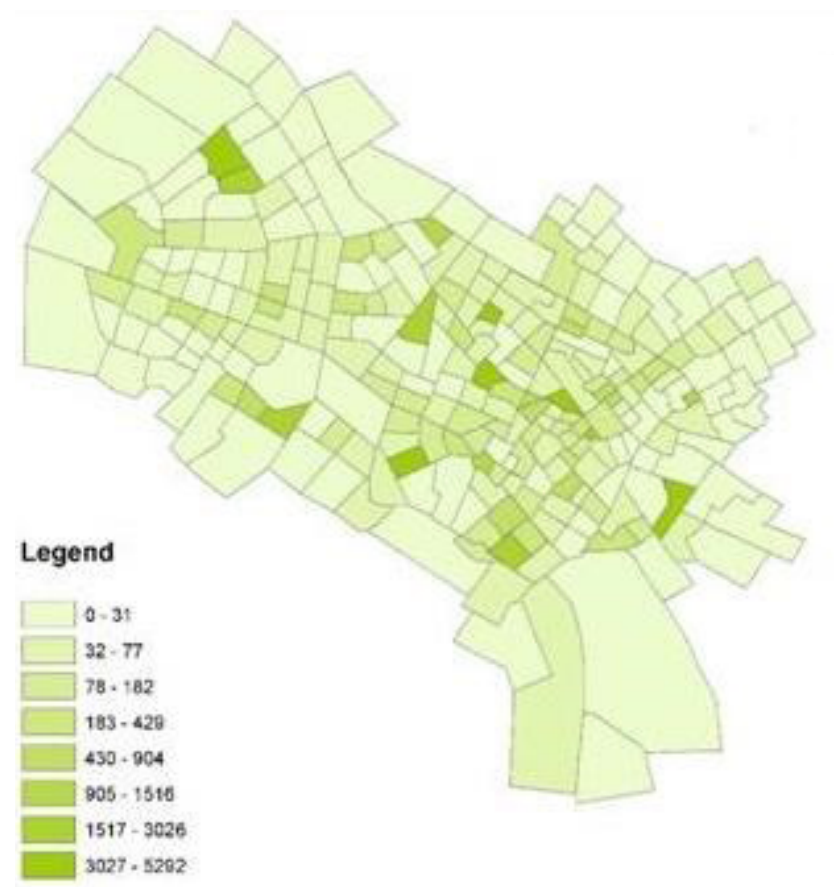

The hypothesis is that $A_{m}$ is significantly higher than $A_{c}$. For testing the hypothesis, an independent samples T-test was performed using SPSS software, and the results are shown in Tables 2 and 3. According to the obtained results (sig.<0.05), the hypothesis is confirmed. 
TABLE 2.

Group Statistics

\begin{tabular}{|c|c|c|c|c|c|}
\hline & Groups & N & Mean & $\begin{array}{c}\text { Std. } \\
\text { Deviation }\end{array}$ & $\begin{array}{c}\text { Std. Error } \\
\text { Mean }\end{array}$ \\
\hline $\begin{array}{c}\text { Mean } \\
\text { access level }\end{array}$ & 1 (Current) & 253 & 0.0775 & 0.11260 & 0.00708 \\
\cline { 2 - 6 } & 2 (Modified) & 253 & 0.2393 & 0.71228 & 0.04478 \\
\hline
\end{tabular}

TABLE 3.

Independent Samples Test

\begin{tabular}{|c|l|c|c|c|c|c|}
\hline \multicolumn{2}{|c|}{} & \multicolumn{3}{|c|}{$\begin{array}{c}\text { Levene's Test for } \\
\text { Equality of Variances }\end{array}$} & \multicolumn{3}{|c|}{ T-Test for Equality of Means } \\
\cline { 3 - 8 } & $F$ & Sig. & $t$ & $d f$ & Sig. (2tailed) \\
\hline $\begin{array}{c}\text { Mean } \\
\text { access level }\end{array}$ & Equal variances assumed & 40.496 & 0.000 & -3.569 & 504 & 0.000 \\
\cline { 2 - 8 } & Equal variances not assumed & & & -3.569 & 264.588 & 0.000 \\
\hline
\end{tabular}

\section{Conclusion and Recommendations}

The origin of speed- and movement-based thoughts in urban transportation planning goes back to the 1950s-70s, the period of personal cars dominance in cities of industrialized countries. Today, to overcome the traffic issues of large cities and their associated heavy costs (air pollution, loss of citizen time, consumption of limited energy sources), urban sustainability has gained considerable attention and, accessibility is of particular importance for urban planners. In this context, public transport needs more consideration due to its key role in urban movement, and increasing its level of accessibility can be basic factor in encouraging people to use transit instead of cars. Accessibility is the main feature of public transportation in sustainable cities. Therefore, due to the importance of public transport, increasing its coverage level and maximizing its accessibility are regarded as the most important factors in designing the systems. In addition, in designing a framework of public transportation in cities, different criteria should be considered and their optimization requires application of sophisticated methods.

The ant colony algorithm is a well-known method for designing networks and is capable of fulfilling acceptable levels of desirable criteria by correctly defining target functions and limitations. In this research, to maximize the accessibility of a system, population and level of trip-absorbing applications were used as target functions, and the remaining effective factors were defined as limitations. The results show that the produced framework of public transportation, in comparison with the existing network, has a significant difference in terms of increasing accessibility and has higher coverage. Also, as physical limitations of the passages were considered in solving the algorithm, the proposed network will face fewer problems in the implementation step.

The results of the present study show the conflict of two thoughts-development based on mobility and development according to accessibility principles. Therefore, by adapting each way of thinking, designers of public transport systems can obtain different results, the neglect of which could lead to considerable negative consequences.

The following suggestions are presented for definition and future studies: 
- As traffic consultants usually consider the same principles for public transport design, this study shows the difference between public transport design according to sustainable development principles (accessibility) and movementbased methods; it is suggested to conduct similar studies in the other countries and apply the required modifications in future developments.

- The ant colony algorithm is based on a target function definition, as various parameters such as passed time, level of limited sources of energy consumption, extent of production and absorption of trips, level of environmental pollutant production, and level of costbenefit can be placed in the target function. It is suggested to change the target function and compare the newly-produced networks in terms of coverage level and accessibility index.

\section{References}

Ayati, E., and M. Bagheri. 2006. "Coverage Method for the Location of a Light Rail Transit (LRT)." Transportation Research Journal (Pajouheshnameh Haml va Naghl), 3: 1-11.

Behbahani, H., and H. Asadikiya. 2010. "Assessment Strategies in Intelligent Transportation Systems (ITS) of Traffic Safety View Point." 10 $0^{\text {th }}$ international Conference on Traffic \& Transportation Engineering, Tehran, Iran.

Dorigo, M., and T. Stutzle. 2004. Ant Colony Optimisation. Boston: MIT Press.

Dorigo, M., V. Maniezzo, and A. Colorni. 1996. "The Ant System: Optimization by a Colony of Cooperating Agents." IEEE Transactions on Systems, Man, and Cybernetics-Part B, 26(1): 1-13.

Ghoseiri, K., and F. Morshedsolouk. 2006. "ACS-TS: Train Scheduling Using Ant Colony System." Journal of Applied Mathematics and Descision Science: 1-28.

Goss, S., S. Aron, J. L. Deneubourg, and J. M. Pasteels. 1998. "Self-Organized Shortcuts in the Argentine Ant." Naturwissenschaften, 76: 579-581.

Handy, S. L., and D. A. Niemeier. 1997. "Measuring Accessibility: An Exploration of Issues and Alternatives." Environment \& Planning A, 29(7): 1175-1194.

Hansen, W. 1959. "How Accessibility Shapes Land Use." Journal of the American Institute of Planners, 25(1): 73-76.

Harris, B. 2001. "Accessibility: Concepts and Applications." Journal of Transportation and Statistics, 4(2/3): 15-30.

Hosapujari, A. B., and A. Verma. 2013. "Development of a Hub and Spoke Model for Bus Transit Route Network Design." Procedia - Social and Behavioral Sciences: 835-844.

Kaphle, I. 2006. “Evaluating People's Accessibility to Public Parks using Geographic Information Systems: A Case Study in Ames, lowa." lowa State University.

Litman, T. 2011. "Measuring Transportation: Traffic, Mobility and Accessibility. " Victoria Transport Policy Institute, www.vtpi.org. 
Mandl, C. E. 1979. "Evaluation and Optimization of Urban Public Transportation Networks." European Journal of Operational Research, 5: 396-404.

Nuzzolo, A., P. Coppola, and E. Papa 2014. "Marginal Activity Access Cost (MAAC): A New Indicator for Sustainable Land Use/Transport (LUT) Planning." Procedia Social and Behavioral Science, 111: 450-459.

Pardo, C. F. 2010. "Challenges of Urban Transport in Developing Countries-A Summary." www.sutp.org.

Rahnam, M. R., and H. Aghajani. 2013. "Analysis of Accessibility Index in Mashhad city." Journal of Geography and Regional Development, 20: 43-58.

Rahnam, M. R., and H. Forghani. 2008. "Planning on Bus Accessibility in Iran, Case Study Mashhad City." Journal of Spatial Planning, 12(2): 73-96.

Sivakumaran, K., Y. Li, M. Cassidy, and S. Madanat. 2014. "Access and the Choice of Transit Technology." Transportation Research Part A: Policy and Practice, 59: 204221.

Transport Research Center of Sharif Industrial University. 2003. “Designing the LRT Lines in Mashhad." Traffic and Transport Organization of Mashhad Municipality.

Transport Research Center of Sharif Industrial University. 2008. "Designing the BRT lines in Mashhad," Traffic and Transport Organization of Mashhad Municipality.

Uchimura, K., H. Takashi, and T. Saitoh. 2002. "Demand Responsive Services in a Hierarchical Public Transportation System." IEEE Transactions on Vehicular Technology, 51: 760-766.

Xiaosu, M. A., and K. L. Hong. 2013. “On Joint Railway and Housing Development Strategy." Transportation Research Part B, 57: 451-467.

\section{About the Authors}

Houman Shadab Mehr (Ho_sh852@stu-mail.um.ac.ir) is a Ph.D. candidate in Geography and Urban Planning at Ferdowsi University of Mashhad, International Campus.

Mohamad Rahim Rahnama (rahnama@um.ac.ir) is with the Department of Geography and Urban Planning at Ferdowsi University of Mashhad.

Moнamad AJza Sнокоuн (Shokouhim@um.ac.ir) is with the Department of Geography and Urban Planning at Ferdowsi University of Mashhad.

Ezatollah MAFi (mafi@um.ac.ir) is with the Department of Geography and Urban Planning at Ferdowsi University of Mashhad. 